Boot, C.R.L., Meijman, F.J., Dulmen, S. van. Beliefs about the causes of health complaints: a study in primary care. Health Communication: 2009, 24(4), 346-350

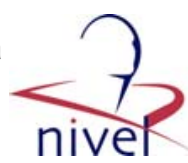

\begin{tabular}{|l|l|}
\hline $\begin{array}{l}\text { Postprint } \\
\text { Version }\end{array}$ & 1.0 \\
\hline Journal website & $\underline{\text { http://dx.doi.org/10.1080/10410230902889373 }}$ \\
\hline Pubmed link & $\underline{\text { http://www.ncbi.nlm.nih.gov/pubmed/19499428 }}$ \\
\hline DOI & $10.1080 / 10410230902889373$ \\
\hline
\end{tabular}

This is a NIVEL certified Post Print, more info at http://www.nivel.eu

\title{
Beliefs About the Causes of Health Complaints: A Study in Primary Care
}

\author{
CÉCILE R. L. BOOT AND FRANS J. MEIJMAN Department of Metamedica/Medical \\ Humanities VU University Medical Centre, Amsterdam, The Netherlands \\ SANDRA VAN DULMEN Netherlands Institute for Health Services Research, Utrecht, The \\ Netherlands
}

In public and interpersonal health communication, a need exists to explore the nature of lay beliefs about health complaints to achieve effective communication. Beliefs of patients visiting their family physician/general practitioner (GP) may give insight into this matter. The aim of this study was to investigate the spectrum of causes attributed to different categories of health complaints presented at the GP office. Before visiting their GP, 2,253 individuals completed a questionnaire about their health complaint and the cause they attributed to this complaint. The spectrum of causes attributed to all health complaints was compared between distinct categories of health complaints. Sixty-two percent of the GP patients attributed at least 1 cause to health complaints they presented at the GP office. Thirty-eight percent of GP patients did not attribute a cause to the health complaint they presented at the GP office. Patient beliefs differed across distinct health problems. Lay beliefs seemed to differ from basic notions of illness because patients attributed different causes to different health complaints. These differences in beliefs, when patients choose to share them with their GP, may serve as a starting point for the communication between the patients and the GP to achieve an effective communication. A need seems to emerge to discriminate between lay beliefs regarding the nature of specific illnesses and those regarding basic notions. GPs are therefore advised to attend to, or at least ask for, their patients' views specifically .

The key to the success of public health communication is the interaction between the sender and the receiver by exchanging rather than simply transmitting information (Lee \& Garvin, 2003). When the sender wants the message to be heard, knowledge of the public beliefs about specific matters of health and disease is indispensable. These health beliefs of the public should be the starting point when designing public health messages .

As with health-care professionals, the causes people attribute to their health problems reflect their beliefs regarding their health complaints (Bury \& Wood, 1979). These health beliefs and, in particular, the causes they attribute to their health problems determine to a large extent whether or not they decide to consult a physician (Cameron \& Leventhal, 2003). In a recent study on health beliefs, it was shown that a low level of perceived susceptibility to develop carpal tunnel syndrome interfered with persons' helpseeking behavior (Martin, 2007). Another study reported associations between causal attributions of mental distress and attitudes toward seeking help, although differences existed between cultures (Sheikh \& Furnham, 2000). Cultural differences in health beliefs form a major factor in poor communication between physicians and patients . 
Boot, C.R.L., Meijman, F.J., Dulmen, S. van. Beliefs about the causes of health complaints: a study in primary care. Health Communication: 2009, 24(4), 346-350

Other researchers have shown that health beliefs play an important role in treatment adherence. For example, Kressin et al. (2007) reported associations between believing that one's blood pressure continues to be high and worse treatment adherence. Another study showed that beliefs about perceived treatment utility were associated with poor medication adherence in HIV-positive adults (Barclay et al., 2007). In a study conducted in primary care, it was concluded that health beliefs regarding the seriousness of asthma were associated with treatment adherence to corticosteroids (Chambers, Markson, Diamond, Lasch, \& Berger, 1999). Previous work has supported the view that people tend to look for external or environmental, rather than internal, explanations for bodily sensations (Robbins \& Kirmayer, 1991). The question rises as to whether these external explanations reflect general views, notions, or beliefs about health and disease. Do the causal attributions of the public predominantly reflect stable basic notions and emotional understanding of illness? Or is it possible to distinguish between differentiated and intellectual features of lay beliefs? This is important because communication about specific beliefs differs from communication about basic notions or general health beliefs (Van der Sanden \& Meijman, 2008). Another point of interest is whether these causal attributions are associated with the type of health complaint. Do people attribute one cause to all health complaints, or do the causal attributions of the public depend on the type of health complaint? If the physician understands the patient's health beliefs and perspectives regarding their illness and health complaints, they can incorporate this knowledge into their treatment or management to improve health outcomes . Although many studies have focused on health beliefs in general and causal attributions in particular, most studies of causal attributions have been conducted in specific subsets of the public, such as patients suffering from a particular chronic illness (Barclay et al., 2007; Chambers et al., 1999) . Other studies investigated causes attributed to several illnesses in people who did not have the specific illness at the moment of investigation (e.g., Blaxter, 1983; Lauber, Falcato, Nordt, \& Rossler, 2003) .

Causal attributions may differ between people who do and who do not suffer from the health complaints at the moment they attribute causes. People visiting their general practitioner or family physician (hereafter, GP) make an interesting research population for this study because this group resembles the general public more closely than a sample consisting of only patients with chronic illness. In addition to treating many chronic illnesses, GPs treat common health complaints that do not result from chronic illness . To build on the knowledge from the previously mentioned studies, our study aimed to investigate the spectrum of causes that patients attribute to different categories of health complaints presented at the GP's office .

\section{METHOD}

The aim of this study was to examine causal attributions to distinct health problems in a sample of GP patients in the Netherlands .

\section{Research Sample}

This study is the result of a secondary analysis of part of the material obtained from the Second Dutch National Survey of General Practice, carried out in 2001 by the Netherlands Institute for Health Services Research (Westert et al., 2005) . Within the survey, patients completed a questionnaire before entering the consulting room of their GP.When permitted by the patient in question, 142 GPs were observed by camera during consultations. Patient refusal rate was low (11.9\%). Fifteen to 20 consultations were recorded for each GP, resulting in 2,784 video-observations. The sample characteristics corresponded to the Dutch population (age, sex, type of health insurance). After excluding the 115 patients from whom 
Boot, C.R.L., Meijman, F.J., Dulmen, S. van. Beliefs about the causes of health complaints: a study in primary care. Health Communication: 2009, 24(4), 346-350

no International Classification of Primary Care (ICPC) code was available, as well as patients younger than 18 years, 2,253 patients remained .

\section{Health Problems}

Health problems were coded using the ICPC (Lamberts, 1987). In a study on 30 written patient cases (vignettes), the mean agreement on the ICPC codes assigned to the patients' health problems between GPs and four ICPC experts was 81\% (Lamberts, 1987; Van der Linden, Schellevis, \& Westert, 2006) .

\section{Causal Attributions}

Causal attributions to health problems were investigated in advance of the GP consultation, using the causal dimension of the Revised Illness Perception Questionnaire (Moss-Morris et al., 2002). This dimension comprises 18 items, each representing one of the following causes: self-reported stress or worry; mental attitude; family worries; overwork; emotional state; heredity; eating habits; poor medical care in the past; behavior; personality; aging; smoking; alcohol; germ/virus; environmental pollution; altered immunity; chance/bad luck; and accident/injury. Items were scored on a 5-point Likert-type scale that was dichotomized into "no attribution" (answering categories 1-3: strongly disagree, disagree, neither agree nor disagree) and attribution (answering categories 4 or 5: agree or strongly agree) (Moss-Morris et al., 2002) .

\section{Analyses}

For each causal attribution, the proportion for the total group of patients was calculated by dividing the number of participants with attributions in that category by the total sample $(\mathrm{N}=$ 2,253 ). Next, proportions were calculated separately for each ICPC code (disease category) containing more than 100 participants. These proportions are presented as the top five most frequently mentioned causes per ICPC code. For each cause, the distribution over the distinct health complaints was tested using chi-square tests.

\section{RESULTS}

\section{Frequencies and Spectrum of Causes}

In Table 1, the spectrum of causes for the total group of patients is presented. Sixty-two percent of the participants did attribute at least one cause to their health complaints . Thirtyeight percent of the participants did not attribute a cause to their health complaint. This group consists of two subgroups: the majority did not agree with the causes presented in the questionnaire, and a smaller group did not have an opinion about the causes.

Stress or worries, chance or bad luck, and altered immunity formed the top three of most mentioned causes. The spectrum of attributed causes per category of health problem is presented in Table 2. Chi-square tests could not be performed for the causes "alcohol" and "poor medical care in the past" because too many cells (>30\%) contained fewer than 5 cases. All distributions of the remaining causes differed significantly $(\mathrm{p}<0.001)$ between the distinct categories of health complaints . 
Boot, C.R.L., Meijman, F.J., Dulmen, S. van. Beliefs about the causes of health complaints: a study in primary care. Health Communication: 2009, 24(4), 346-350

\section{[TABLE 1]}

\section{[TABLE 2]}

\section{DISCUSSION}

The main findings of this study were that the majority of GP patients attribute a broad range of causes to health complaints, and that these causes differ across distinct groups of health complaints. Sixty two percent of the sample identified at least one cause, thus suggesting that GP patients have specific thoughts about the causes of specific health complaints rather than general notions about causes that they apply to health complaints in general. Although one third of the participants did not attribute a cause to their health complaints, the majority of the group who did not attribute any cause chose the answering categories "disagree" or "strongly disagree” rather than 'neither agree nor disagree'. Choosing these answers may be considered as a choice as well, although a negative one. The fact that this group of participants did not agree with the mentioned causes implies that they have thoughts or beliefs about the causes of their health complaints as well . It is likely that they have an idea about the causes of their health complaints, but that this option was not on the list in the questionnaire .

It can thus be said that in this study, GP patients had specific thoughts about the causes of their health complaints while visiting their GP. These findings are in agreement with findings from a qualitative study on ideas about disease and illness of women (Blaxter, 1983). The women in the Blaxter study appeared to have specific ideas about disease mechanisms that did not differ from the ideas in medical science, although they were sometimes wrong at factual levels. Because these women were explicitly invited to think about diseases, they did not discuss perceived causes of illnesses. Another study investigated theories of patients with severe physical diseases, such as cancer, female myocardial infarction, and multiple sclerosis, and reported that different predominant causal attributions were found for the distinct diseases (Muthny, Bechtel, \& Spaete, 1992).

\section{Methodological Considerations}

The GPs participating in this study form a representative sample of the general population of GPs in The Netherlands based on information about the GPs' age, sex, geographic distribution of practices, urbanization levels, and distribution of practices in low socioeconomic status areas (Van Dulmen \& Bensing, 2006). When interpreting the results, one should realise that the list of causes does not give a complete overview of potential causes. This dimension of the Revised Illness Perception Questionnaire aims to investigate general perceptions of causes. The aim of this study was different, and as a result, some causes were presented as one item, although the clinical implications of both causes were different, such as the category "germ or virus." We cannot provide information on the total range of beliefs about the causes of illness of the participants of this study because only 18 potential causes were presented to the participants . However, this study was not an attempt to provide insight into which particular causes were chosen but rather to compare the spectra of attributed causes between disease categories and within the group of participants. It can be expected that if we had provided more choices for causal attribution, the differences between the spectra of causes attributed to the different health problems would have increased rather than decreased .

\section{Implications for Practice}

The primary implication of this study is that the GP patients have specific thoughts and feelings about the causes of their health complaints: they have specific and differentiated 
Boot, C.R.L., Meijman, F.J., Dulmen, S. van. Beliefs about the causes of health complaints: a study in primary care. Health Communication: 2009, 24(4), 346-350

ideas about what factors influence their health. When GP patients discuss their causal attributions with their GP during the consultation, these beliefs should be taken into account by the GP to obtain an effective communication during the consultation. However, further research is needed to investigate whether GP patients share, or are willing to share, their beliefs about causes with their GP. Effective communication between the GP and the patient should start at the level of the patient's ideas. In an ideal situation, communication in the GP's office should be a dynamic process in which the views of the patient, which we now know to be not just basic notions, but disease-specific beliefs, are incorporated .

In health communication, a balance should exist between discussing lay and professional beliefs and goals before developing an intervention. As patients' views regarding disease causes are likely to change under the influence of the information exchange during the GP visit, inquiring about causes at follow-up should be encouraged as well. Although many investigators have pleaded for an exchange of information rather than a oneway transmission, this is still not common practice in the physician's office (Lee \& Garvin, 2003)

\section{From Patient Communication Toward Public Health Communication}

A continuum exists between expert and lay knowledge, with experts on one side and lay people on the other. Chronically ill are experts in the domain of their illness or disease, and the lay public is placed on the other side of the knowledge continuum. The level of knowledge of health and disease for GP patients as a group, consisting of chronically ill as well as lay people, can be placed in between the chronically ill and the public. Taking this into account, lessons learned in this study of GP patients may be applicable to the public, although caveats should be kept in mind .

When GP patients have explicit beliefs about the causes of their health complaints, it may be expected that the general public will have differentiated beliefs about causes of health complaints as well. More research is needed to confirm these expectations; it would be interesting to know whether GP patients have ideas about health complaints that are not their own; for example, when personal factors such as a tobacco addiction are not involved, it may be easier to point the finger to others and say that smoking is the cause of their cough, instead of a virus. In addition, it will be of great value to investigate which specific ideas the general public has about causes of distinct health complaints in order to develop effective public health campaigns. It can be expected that, like communication between GP and patient, public health communication requires a dynamic rather than a static approach (Van der Sanden \& Meijman, 2008) .

\section{Conclusion}

Beliefs of GP patients appear to be specific for distinct health problems in primary care. When patients share their beliefs with their GP, these beliefs should be incorporated into the communication during consultation .

\section{REFERENCES}

Barclay, T. R., Hinkin, C. H., Castellon, S. A., Mason, K. I., Reinhard, M. J., Marion, S. D., et al. (2007). Age-associated predictors of medication adherence in HIV-positive adults: Health beliefs, self-efficacy, and neurocognitive status. Health Psychology, 26, 40-49 .

Blaxter, M. (1983). The causes of disease. Women talking. Social Science \& Medicine, 17, $59-69$.

Bury, M. R., \& Wood, P. H. (1979). Problems of communication in chronic illness. International Rehabilitation Medicine, 1, 130-134 . 
Boot, C.R.L., Meijman, F.J., Dulmen, S. van. Beliefs about the causes of health complaints: a study in primary care. Health Communication: 2009, 24(4), 346-350

Cameron, L. D., \& Leventhal, H. (2003). The self-regulation of health and illness behaviour. London: Routledge .

Chambers, C. V., Markson, L., Diamond, J. J., Lasch, L., \& Berger, M . (1999). Health beliefs and compliance with inhaled corticosteroids by asthmatic patients in primary care practices. Respiratory Medicine, 93, 88-94 .

Kressin, N. R., Wang, F., Long, J., Bokhour, B. G., Orner, M. B., Rothendler, J., et al. (2007). Hypertensive patients' race, health beliefs, process of care, and medication adherence. Journal of General Internal Medicine, 22, 768-774 .

Lamberts, H. (1987). International classification of primary care. Oxford, UK: Oxford University Press .

Lauber, C., Falcato, L., Nordt, C., \& Rossler, W. (2003). Lay beliefs about causes of depression. Acta Psychiatrica Scandinavica Supplementum, 418, 96-99 .

Lee, R. G., \& Garvin, T. (2003). Moving from information transfer to information exchange in health and health care. Social Science \& Medicine, 56, 449-464 .

Martin, H. (2007). Patients' health beliefs and adaptation to carpal tunnel syndrome based on duration of symptomatic presentation. Journal of Hand Therapy, 20, 29-35 .

Moss-Morris, R., Weinman, J., Petrie, K. J., Horne, R., Cameron, L. D., \& Buick, D. (2002). The revised illness perception questionnaire (IPQ-R) . Psychology \& Health, 17, 1-16 .

Muthny, F. A., Bechtel, M., \& Spaete, M. (1992). Lay etiologic theories and coping with illness in severe physical diseases. An empirical comparative study of female myocardial infarct, cancer, dialysis and multiple sclerosis patients [in German]. Psychotherapie, Psychosomatik, medizinische Psychologie, 42, 41-53.

Robbins, J. M., \& Kirmayer, L. J. (1991). Attributions of common somatic symptoms. Psychological Medicine, 21, 1029-1045.

Sheikh, S., \& Furnham, A. (2000). A cross-cultural study of mental health beliefs and attitudes towards seeking professional help. Social Psychiatry and Psychiatric Epidemiology, 35, 326-334 .

Van der Linden, M. W., Schellevis, F. G., \& Westert, G. P. (2006). Morbidity in the population and in general practice. In G. P. Westert, L . Jabaaij, \& F. G. Schellevis (Eds.), Morbidity, performance and quality in primary care: Dutch general practice on stage (pp. 35-44). Oxford, UK: Radcliffe.

Van der Sanden, M. C. A., \& Meijman, F. J. (2008). Dialogue guides awareness and understanding of science: An essay on different goals of dialogue leading to different science communication approaches. Public Understanding of Science, 17(1), 89-103 .

Van Dulmen, S., \& Bensing, J. M. (2006). Communication in general practice . In G. P. Westert, L. Jabaaij, \& F. G. Schellevis (Eds.), Morbidity, performance and quality in primary care: Dutch general practice on stage (pp. 170-176). Oxford, UK: Radcliffe .

Westert, G. P., Schellevis, F. G., de Bakker, D. H., Groenewegen, P. P., Bensing, J. M., \& Van der Zee, J. (2005). Monitoring health inequalities through general practice: The Second Dutch National Survey of General Practice. European Journal of Public Health, 15, $59-65$. 
Boot, C.R.L., Meijman, F.J., Dulmen, S. van. Beliefs about the causes of health complaints: a study in primary care. Health Communication: 2009, 24(4), 346-350

TABLES

TABLE 1

Spectrum of Causes Attributed by the Total Group of Patients

\begin{tabular}{lcr}
\hline Causes & $\mathrm{n}$ & $\%$ \\
\hline 1. No cause & 853 & 38 \\
2. Stress or wony & 376 & 17 \\
3. Chance, bad luck & 346 & 15 \\
4. Altered immunity & 305 & 14 \\
5. Germ or virus & 293 & 13 \\
6. Heredity-it rums in the family & 282 & 13 \\
7. Aging & 265 & 12 \\
8. My own behavior & 232 & 10 \\
9. Overwork & 224 & 10 \\
10. My emotional state & 205 & 9 \\
11. Accident or injury & 158 & 7 \\
12. Family problems or wonies & 132 & 6 \\
13. My personality & 127 & 6 \\
14. Diet or eating habits & 107 & 5 \\
15. My mental state & 106 & 5 \\
16. Smoking & 71 & 3 \\
17. Pollution in the environment & 51 & 2 \\
18. Poor medical care in the past & 40 & 2 \\
19. Alcohol & 24 & 1 \\
\hline
\end{tabular}

TABLE 2

Spectrum of Causes Attributed by the Patients for Seven Groups of Health Complaints/Problems With $\geq 100$ Cases

\begin{tabular}{|c|c|c|c|c|c|c|}
\hline \multirow[b]{2}{*}{ Diagnosis Group } & \multirow[b]{2}{*}{$\mathrm{N}$} & \multicolumn{5}{|c|}{ Fine Most Frequently Atrvibuted Causes } \\
\hline & & 1 & 2 & 3 & 4 & 5 \\
\hline Generic complaints & 170 & No cause & Altered immunity & Stress/womies & Heredity & Emotional state \\
\hline Percentage $(\%)$ & & 42 & 20 & 19 & 13 & 11 \\
\hline Musculoskeletal system & 562 & No cause & Chance/bad luck & Accident or injury & Overwork & Own behavior \\
\hline Percentage $(\%)$ & & 35 & 25 & 18 & 16 & 14 \\
\hline Digestive tract & 129 & No cause & Stress/wonies & Germ/virus & Altered immunity & Chance/bad luck \\
\hline Percentage $(\%)$ & & 43 & 19 & 18 & 15 & 12 \\
\hline Psychological disorders & 125 & Stress/womies & Emotional state & Mental state & Family womies & Own behavior \\
\hline Percentage $(\%)$ & & 68 & 55 & 32 & 31 & 30 \\
\hline Circulatory tract & 281 & No cause & Heredity & Stress/wonies & Aging & Overwork \\
\hline Percentage (\%) & & 41 & 24 & 23 & 15 & 11 \\
\hline Respiratory tract & 253 & Germ/virus & Altered immunity & No cause & Heredity & Stress/wonies \\
\hline Percentage $(\%)$ & & 42 & 34 & 30 & 17 & 13 \\
\hline Skin disorders & 208 & No cause & Chance/bad luck & Germ/virus & Heredity & Stress/wonries \\
\hline Percentage $(\%)$ & & 44 & 21 & 20 & 12 & 8 \\
\hline
\end{tabular}

Note. Participants were asked to rate their agreement for each cause. Consecquently, participants were able to agree with more than one cause, which explains the row totals of more than $100 \%$. 